\title{
The Decorative Orientations in the Mediterranean Architecture and its Influence on the Development of Cultural Sustainability
}

\author{
Sara Hukmat ${ }^{1}$, Havva Arslangazi Uzunahmet ${ }^{1}$
}

\begin{abstract}
This paper attempts to describe the different orientations in architectural decoration that arose as a result of human existence and its relation to his environment. Throughout history, decoration has been a bridge connecting the building to the environment, connecting people with history and culture. And it has been an instrument of the local identity of the building and the whole environment within the framework of the idea of sustainability, which consists of three foundations (economic, environmental and cultural). Within this texture in this study, decorative details and patterns are evaluated, in order to understand the effects of factors on cultures. From one culture to another, it is discussed in connection with the comparison of the Moorish and Greek decoration. As a result, this study has determined decorative orientations in the Mediterranean architecture and its influence on sustainable development.
\end{abstract}

Keywords: Decoration, Cultural Sustainability, Style, Identity, Greek, Moorish

\section{Introduction}

According to the overview of the history of old and current Mediterranean architecture and the idea of sustainability, which consist of three basic (economic, ecological and cultural) foundations, features of sustainable culture is the identity (Abulafia, D., 2003; Braudel, F., 1995). Indeed, the spaces have been inhabiting a significant role in moldings individually, whether it be in the home or workplace. The spaces in which have been lived to play an important role in human identity, and through these spaces, human add part of their personality to the components that surround them and thus they are part of their surroundings (Herrle, P., Wegerhoff, E., Eds., 2008).

Cultural sustainability has long been categorized within the social pillar of the three pillars of sustainability, but with recent developments in this area, considerations are being made to make cultural sustainability its own. This makes it even more challenging for architects when designing a new building. The importance of cultural sustainability is affecting society. The building, which falls under a sustainable name, embodies the culture and thought of that society, and then merges with the other three pillars of sustainability (Fiol, C. M. (1991). It must be economical, environmental and social. What makes a society proud of its culture and history is its own identity that reflects its ideas. Therefore, anything that reflects the views of the culture of a society in the building, whether in the form or decoration or distribution of spaces gives it a special character and identity for that building (Hegazy, S. M., 2015; Memmotta, P., Keys., C., 2015). 
Lands around the Mediterranean Sea had communication through the ages. It had a more closed character in the world. Cultures that live together depends on ethnic, economic, and religious differences. Many important civilizations emerged around the Mediterranean; it was an important route for traders and travellers during ancient times, helping trade and cultural exchange among the peoples of the region; it is used to describe construction techniques that have distinct Mediterranean effects. This type of architecture combines a range of building patterns commonly found in countries around the Mediterranean such as Spain, Italy, Croatia and North Africa (Maalouf, A., 2002).

Architecture is part of the identity of each community and carries the message as concept and characteristics attributed to the community where it was born. Therefore, it depends on the geography, traditions, manners, insights and knowledge of the community as well as its history. It can show all these dependencies of the community as well as its history (Herrle, P., Wegerhoff, E, 2008) and besides the main characteristics of architecture identity: Meaningful and understandable places are suitable bases for personal memories, feelings and values. Such that Lynch considers two major functions of identity. The first function is a sense of recognition. In other words, identity gives human judgment ability and helps them understand and predict the environment. The second one is the emotional function of environmental identity. The design in architecture is considered as a simple matter, but it has also so difficult issues. Creating space appears easy but in fact, is very complex and deep. It is well proven that people are affected by the environment. Human intervenes in the natural environment and builds and organizes artificial environment where they can live. Types of human intervention in nature for creating a variety of architectural spaces have changed during history (Torabi, Z., Brahman, S., 2013).

Decoration of material, designed to add quality features to besides their quantitative states. This process involves the individual's efforts in thinking, design, creativity and communication. Human figures are used as little as possible, and if they exist, they are small compared to the general scale. Architectural decoration can be carved out of stone, wood or precious metals, made of plaster or clay, or painted on the surface to be decorated. The architecture is the environment in which the decoration grows.

Decorative arts must be the subject to the architectural environment (internallyexternally). Moreover, they have played a great role in buildings' elevations in the Paranoiac, Greek, Christian, Islamic architecture that distinguishes each building and gives the common form to it. Columbia University professor A.D.F. Hamlin classified architectural decoration according to its way of covering space, the means of its production, the principles guiding its design, the object to which it is applied, and its relation to structure subdivided into the categories of regularization, abstraction, exaggeration, multiplication, and combination (Fiol, C. M., 1991; Hamlin, A.D.F., 1916). The ornament could be applied to architecture or to objects of industrial products such as furniture and clothing. James Trilling recently outlined a classification system based on a series of dialectical concepts: movement versus stasis, grace versus strength, determinacy versus indeterminacy, comprehensibility versus complexity, stylization versus literalism, virtuosity versus truth to materials, application to versus integration with the object, convention versus innovation, the maker's versus the patron's 
imagination, and local tradition versus outside (Trilling, J., 2001). Each country sought the models for its own Decoration in its own Fauna and Flora, and each style had certain plants and animals which is preferred to all others. Style is really more the product of one epoch of time rather than of a single person. Decoration increased over the Romanesque and Gothic but was greatly reduced in Early Renaissance styles, again under the classical influence. Other periods of increase are Northern Mannerism, the Baroque and Rococo (Sağlam, H., 2014; Mitrache, A., 2012).

What distinguishes the building or any other notable structure in history is the architectural style. The style includes elements such as the shape, construction method, and materials in which they were created. Most buildings can also be classified as a chronology of patterns that change over time. In the same geographical area, functional therapies can be repeated in a similar way, but the pattern of decoration of these functional therapies varies according to ideas and opinions. Based on several factors that will be mentioned in this paper. The birth of any style differs from the previous pattern, for example, based on religion - Dravidian style, Islamic style. Based on Structural Techniques - Egyptian and Greek, Wet Roman System, Gothic Arch System, Early Christian (Bayard, E., 2012).

The concept of decoration is culturally conditioned. For example, Eastern culture displays decorations as a component part of the surface composition of architecture. Unlike, Western culture has decorations as supplementary element to use on surfaces or architectural formations (Vick, B. 2018; Jones, M. W. 2014; Rushda I., 2014; Burckhardt, T. 2009; Marconi, C., 2007). Expression through decoration and ornament depends on six basic factors such as geography, geology, climate, religion, policy, history that will be mentioned in this brief research and culture carried by man reflects in many ways, including decoration, for example, it is founded that the eastern human loves to look at the architectural surface and inscriptions that it is not an addition to the surface, but it is an integral part of the surface itself. In Western decorations, they look at the architectural surface and decoration on which it is part of the host and not complementary to it (Sağlam, H.,2014; Mitrache, A., 2012).

Depends on conditions of the period, occasionally decoration had been seen lost labor and time instead of the component part of architecture (Long, C. 2009; Loos, A. 1998). But how if it is perceived as an identity of civilization (Speltz, A. 1959), and as a result, this research comes to find out how ancient buildings and civilizations were able to express their identity and originality through architectural decoration. Is it possible that the decorations reflect the orientations of any civilization?

The purpose of this study is to identify decoration and their origins in Moorish and Greek architecture. With the study, it was hoped to develop an understanding of how the decoration effect on the identity definition of the different style in the Mediterranean architecture. And how the different cultures traditionally understood for decorating with this, the vary decorations in architecture, the main research problem could be defined as what is the result of a comparison of the Moorish and Greek decorations and its influence on sustainable development. 


\section{Styles of Decoration in the Mediterranean Architecture}

While architecture maintains to transform and change, some of the older models and styles of construction survived relatively. It can be seen all over the world, whether in buildings, mosques, museums or art galleries. Each of the largest cities in the world boasts a range of architectural styles that give a different impression of other cities. An architectural style is a collection of features and features that enable us to easily identify any building. It may include materials used in construction or even construction (Fletcher, B. 1931; Ward, J., (1897-1909 (v. 1, 1909).

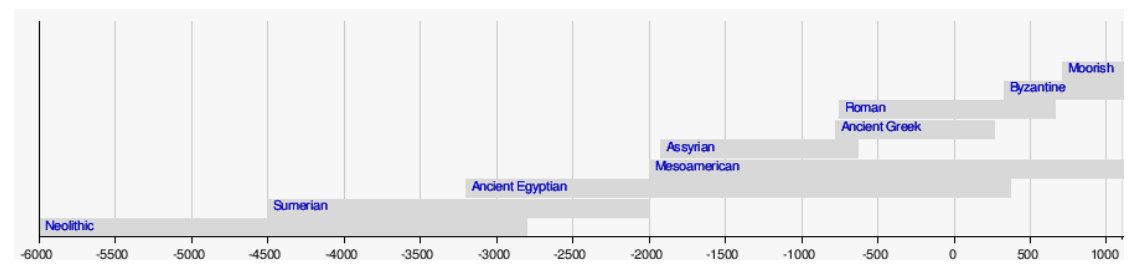

Figure 1. The Place of Antique Greek and Moorish Architecture in Timeline of Mediterranean Architectural Style. (Maalouf, A., 2002)

In an architectural style is characterized by the features that make a building or other structure notable and historically identifiable. A style may include such elements as form, method of construction, building materials, and regional character. Usually repetition of features like columns, courtyards, decoration, openings etc. are seen. Roof and façade treatments all are repeated in a similar fashion of a particular area or time such as: based on region -Egyptian, Roman, Greek etc.; based on religion -Dravidian Style, Orissan Style, Vijayanagar Style; based on structural techniques -Egyptian and Greek: Trabeated system (Bayard, E., 2012).

Mediterranean is a region having countless cultures and civilizations occurred through the ages. Hence many important architectural styles have appeared around it (Abulafia, D., 2003; Maalouf, A., 2002; Braudel, F., 2002; Braudel, F., 1995). From them, two different styles were chosen for the research problem of paper; Greek and Moorish (Figure 1). Each had its own style of decoration and to express their own identity as common points. When styles of architecture and decoration have been forming, influenced by many factors. Six specific factors that were selected to influence to these historic styles of architecture and decoration; geography, geology, climate, religion, policy, history. All of these provide to economic, environmental and cultural sustainability. The geographical influence, which determines the mode of living, and the means of communication and transportation. The geological one, which determines the quality of the buildings, as the presence or the absence of building stone, clay, or wood will determine whether the buildings shall be of stone, brick, or timber. The influence of climate, which determines the character of the buildings themselves, the size of their windows, and the projection and inclination of the roofs, having a courtyard. The religious influence, which will affect the habits and customs of the people. The political one, as the system of government, will reflect the manners and temperaments of the influential a portion of the nation. The historical influence, worked by the traditions and achievements of previous generations (Bayard, E., 2012; Fletcher, B. 1931). 


\section{Greek Decoration}

Ancient Greeks created many forms of architecture like temples, theatres and statues. The Greek people used art in their daily life. They made art on the buildings. Some people lived in smaller houses or huts with a lot of artistic designs. They made a huge, famous, statue of Athena made of wood, ivory, and gold. That statue rose 40 feet high (12m), as high as a four-story building (Lomas, K. (Ed.)., 2003).
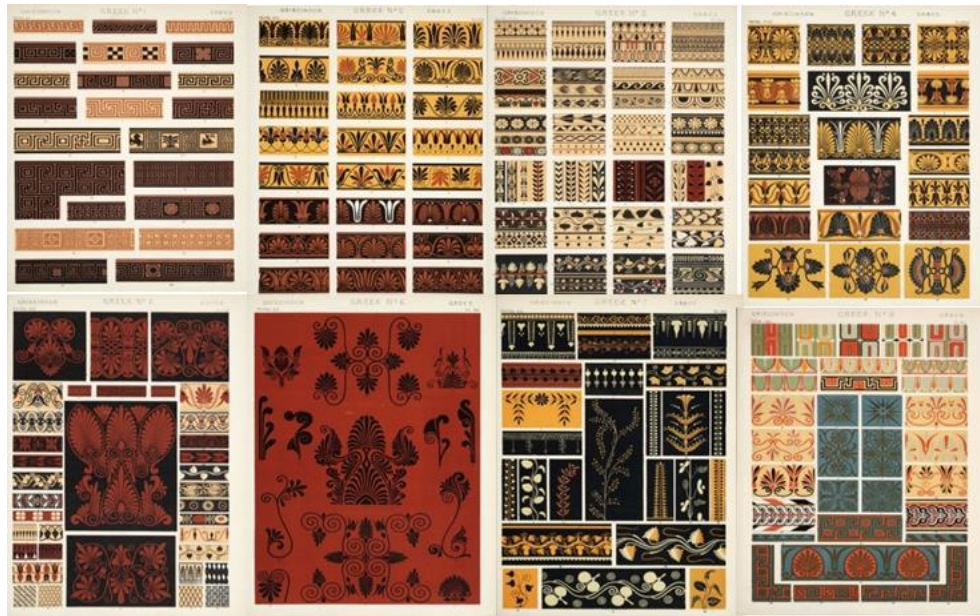

Figure 2. Characteristic Greek Motives (Jones, O., 1856)

Although the three great decorative styles of Greek construction were developed simultaneously, still the general employment of each separate style enables a chronological division to be made. The Doric must be described as the oldest style, but its strongly marked, earnest character, unsuitable for rich decoration, partly superseded by the Ionic, and, later on, by the Corinthian style (Coulton, J. J., 1982). The decoration in these or two styles allowed more play to the artist's fancy and was not so binding in its rules as the Doric. The quiet harmony peculiar to the Doric was, however, lost; ornamentation became predominant and, later on, tended to mask the masonic form in Roman art (Marconi, C. 2007; Dresser, C. 1986; Jones, O., 1856).

In Greek art, in order to supply motifs for the graceful scrolls that appear so frequently, the artist did not hesitate to draw inspirations from such homely growths as pumpkin and squash vines, the details of which were conventionalized into the forms. Greek art carried the perfection of pure form to a point that has never since been reached and the abundant remains of Greek ornament compel human to believe that refined taste was universal and that the country was overflowing with skilled hands and minds so traded as to enable them to execute these beautiful ornaments with unerring precision and truth (Figure 2) (Jones, O., 1856).

\subsection{The Factors Influencing Greek Decoration}

Greek decoration was influenced by regional factors like geography, geology, climate, religion, policy, history, as well as many historic styles. Geographically, the map 
of Greece a small country projecting into the Mediterranean Sea, there are numerous islands scattered about its coast and many natural harbors that the natives found convenient for the development of trade and commerce. The country itself was active on account of the population concentrated along its seacoast, but the mountainous character of the interior prevented any overland means of communication (Van Loon, H.W., 1938; Robinson, H., 1949; Jones, O., 1856). The Greek Art is described as its rationality, simplicity, and harmonious balance. This explains with its lucidity of atmosphere inducing clarity of mind. Furthermore, the Greek decoration has orderly many plant motives, animal figures, and geometrical patterns related to its region (Figure 3, 4) (Tanner, J., 2001; Van Loon, 1938; Robinson, 1949).

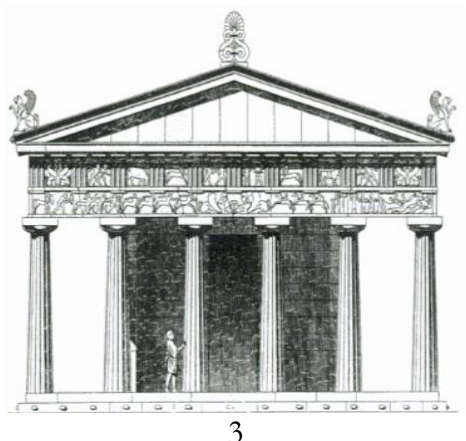

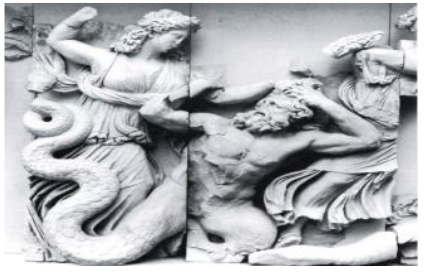

4

Figure 3. Athens. Temple East Restored Front (Marconi, C. 2007; History of Architecture, (1909)1922)

Figure 4. Great Altar of Pergamon: North Frieze. (Schultr, P., Von den Hoff, R.,2014)

The principal geological product of Greece was the finest white marble. It is the best material known for monumental buildings and was found in great abundance in certain localities. The marble also is suited to carving. Therefore, perfectly relieves and sculptures appeared in this region (Robinson, 1949). In other parts of Greek buildings were constructed of bricks. These were occasionally coated with cement composed of marble dust and lime (Figure 6). (Jones, O., 1856)

The climate of Greece varied from extreme tropical heat in summer to the severest cold in winter. The civilization of the country was unique, situated as it was between the rigorous surroundings of Northern Europe and the passive conditions of the Orient, or Southern Asia. The clear atmosphere and intensity of light were conducive for the development of precise, Greek characteristic exact decoration.

Ancient Greek religion was a kind of nature worship grow by the beliefs of previous cultures (Figure 3, 4). Yet, contrary to them, man is no longer seen as subordinate to nature, but he embodies natural elements as gods in a completely human way and human demeanor. It was like many other activities in society, take place outdoors. It was necessary to provide a building that could include statues of the gods, which were often fairly large and this led to the development of temples. It has the central chamber surrounded by upright columns. Earlier ritual offerings to the gods had been made in sacred groves, the trees decorated with the sacrificial offerings. It is believed that the temple, with its surrounding colonnade, was an attempt to re-create the sacred grove. The columns became those decorated trees, and the many parts of the Doric, Ionic, and 
later Corinthian orders were named for the actions performed in these rituals. The architecture seems to have become the concrete form of the ritual (Figure 6) (Da Vignola, G. B., et al., 2011; Roth, 1993).

In the Greek style, because of religious thought found the miniature statues and statues of the gods and the mythical animals. This is also shown in a table \{moldings, architectural elements, column, wall, tessellation, the interior of the courtyard\}. While the influence of nature is clear too. This is due to its influenced by the civilizations that preceded it. In Paranoiac civilization, the pharaoh is glorified and influenced by nature by the Lotus flower, while its influence of the mythical animals came from Assyrian civilizations.

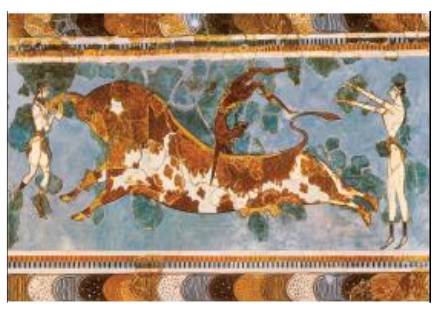

5

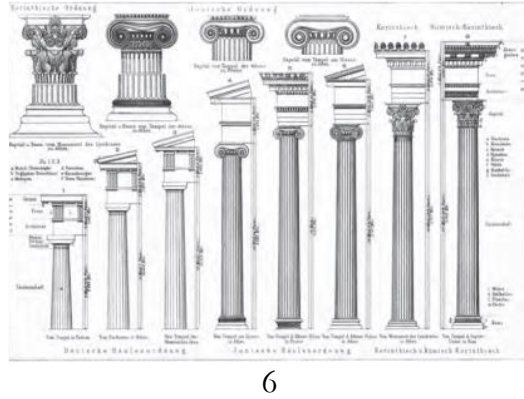

6

Figure 5. Athletes, Shown Vaulting over a Charging Bull, Fresco from the Palace at Knossos (Cavendish, M., 2010)

Figure 6. The Classical Orders as Illustrated in Meyers Kleines Konversations-Lexicon, Vienna,1892-1893. (Massey, J., 2013)

In political side, the people themselves, as a whole, were fond of national games and religious festivals, and thus became united in reverence for their government and their gods (Figure 4). They loved music, drama, and games in physical culture, and liberally patronized the fine arts. They lived an outdoor, open-air life and public ceremonies and courts of justice were frequently conducted in the public squares.

The Greeks history, owing to their geographical surroundings, were naturally colonists, and migrated to the coast of Asia and across the Mediterranean. This emigration was established by the Greek government as early as 700 B. C., both to reduce the crowded population and to encourage trade. The colonies were therefore frequently occupied by people much more enterprising and energetic than those of the mother country. They used as a subject to decorated to their buildings (Figure 4) (Bloomer, K. 2016; Azad et al., 2014).

\section{Moorish Decoration}

The name of Moorish style was given to the medieval art that developed from the 11th to 15 th centuries in North Africa and southern Spain. A blending of the traditions of the Arabian Caliphate, the Berbers, and the Visigoths, was not homogeneous. Developing was different ways in Algeria, Tunisia, Morocco, and Arab (Grünbaum, et al., 1986; Speltz, A. 1928).

Decorative works may be seen in its highest splendor. In the artistic interlacing and interweaving of geometric and arabesque motives. Moorish artists showed extraordinary talent and gave free rein to the wonderful powers of fancy and imagination which they 
possessed in such a high degree. Despite the exuberance of the ornamentation and the rich and vivid colored of the painting, Moorish decoration never wearies or confuses the eye. The technical drawing and the coloring of every single system of decoration is so clearly defined and so distinct, that each can be distinguished from the other easily and clearly (Jones, O., 1856; Grünbaum, et al., 1986; Ward, J.,1897-1909 v. 1, 1909).

In Moorish Art, the decoration arises naturally from the construction, and the idea is carried out in every detail of the ornamentation of the surface. In decorative schemes, the general forms were first subdivided by general lines. Moorish carried out this principle with the greatest refinement, and the harmony and beauty of all their ornamentation derived their chief success from this observance; their main divisions contrasted and balanced perfectly. The detail never interferes with the general form, and, when seen at a distance, the main lines strike the eye and the fine detail disappears; nearer approached, more detail comes into the composition, and, on close inspection, all detail of the surface appears as a grand powdering of ornament. No matter how much the whole ornamentation of the Moorish is disguised, it is all constructed geometrically. Their fondness for geometrical forms is evinced by the great use of mosaics, in which their imagination had fully played. However complicated maybe their patterns. They all arise from the intersection of equidistant sets of lines around fixed centers (Figure 7) (Jones, M. W., 2014).

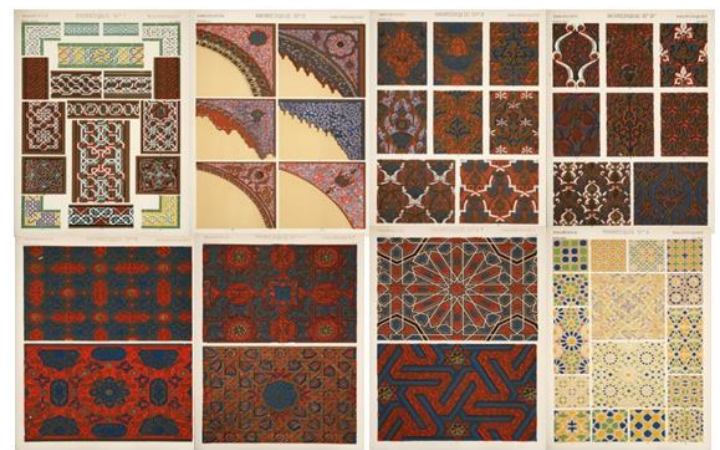

Figure 7. Characteristic Moorish Motives (Jones, O., 1856)

\subsection{The Factors Influencing Moorish Decoration}

Moorish decoration was like the Greek decoration influenced by regional factors geography, geology, climate, religion, policy, history.

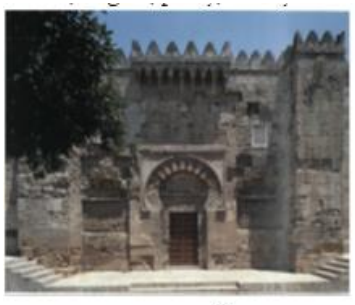

$S$

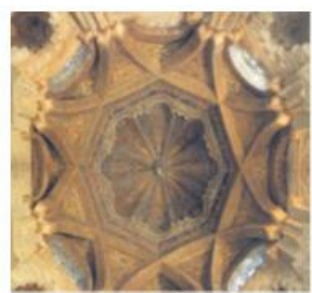

9

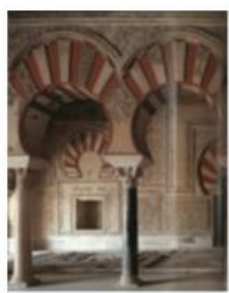

10

Figure 8. Great Mosque, Stephen's Gate, the Former Gate of the Viziers (Barrucand, M. 2007).

Figure 9. Dome on Interlacing Ribs in Front of the Mibrab in the Great Mosque of Cordoba (Barrucand, M. 2007). Figure 10. Madinat al-Zahra; Salon Rico the Rich Hall (Barrucand, M. 2007). 
Geographically, the map of Moorish is a big country projecting into the (northern westsouthern east) the Mediterranean Sea. The country itself was active on account of the population concentrated along its seacoast, and the nearly of the two eares helped the artists have many ideas from the two different culture to make many incredible decorations in their buildings (Van Loon, H.W., 1938; Robinson, H., 1949; Jones, O., 1856). This explains with its lucidity of atmosphere inducing clarity of mind the same with the Greek decoration. Furthermore, the Moorish decoration has orderly many plant motives, animal figures, and geometrical patterns related to its region (Figure 9,10) (Tanner, J., 2001; Robinson, 1949).

Geologically, Moorish architecture was influenced by the nature and colors of the soil, and the different rocks and attractive (Figure 8, 9) (Calvert, A.F., 2010; Barrucand, M. 2007). The climate varied somewhat with the different countries, but the development of the style was confined to eastern and southern countries, so that, generally, the climate was excessively hot. This gave rise to a tendency toward small window and door openings, high ceiling which help them to make many decoration around it (Figure 9).

The Islamic faith and its basic - philosophy, culture, and science - were the Religion crucially influenced the decorative nature of Islamic art throughout the world. The Muslim artist expressed his faith in the Lord with these factors: belief in the One God (Tawheed. ), the concept of beauty and its importance in Islam, hatred of images of human to the degree of symmetry or resemblance to the creation of God and the spirit of special (Figure 9) (Vick, B., 2018; Burckhardt, T., 2009). On another hand politically, the Saracens in the 8th century spread themselves over Northern Africa and Southern Spain. While the rest of the world during the so-called dark ages was plunged into the darkest ignorance, Bagdad in Persia, Cairo in Egypt, and Cordova and Toledo in Spain were centers of brilliant, artistic, and intelligent activity under the Moslem government.

On the historical side, the Saracen Empire was ruled by a caliph, Mohammed being the first. After his death, four other caliphs ruled in succession. Then disputes arose and the empire became divided between two caliphs, one ruling at Bagdad, in Persia, and the other at Cordova, in Spain (Jones, O., 1856). The caliphate of Cordova became divided into the four kingdoms of Seville, Granada, Toledo, and Valentia. These kingdoms were frequently at war with the Christians in Spain, but this did not prevent the Moorish builders from employing Christian workmen on their buildings, and in this manner there was some Gothic influence expressed in their constructions. Each caliph was a spiritual as well as a temporal ruler (Figure 8-10). That is the manner that makes the decoration of some building change during each caliph time. The geopolitics of the country and the integration of many races under its banner and in light of the political entity and cultural one pushed geographical disparities to the forefront in shaping the features of Arab architecture during its long history. It may be said that Moorish architecture is a geographical clash driven by historical reasons.

\section{Methodology}

In order to achieve the research objectives of this study, it had been used a literature review and comparison methods. This review is collected to determine exclusively Greek and Moorish decorations, its influences, and Mediterranean 
Architecture widely. After that, each decoration was compared together with selected data from general ornaments and details such as moldings, architectural elements, column, wall, tessellation, the interior of the courtyard getting from various houses, temples, palaces, etc. Thus it could be answered the relationship with the sustainability of decorative orientations having different and similar identities in the Mediterranean Architecture.

To making the comparison of decoration of these cultures, some selected concepts were used related to architectural decoration: Moldings, architectural elements, column, wall, tessellation, the interior of the courtyard.

Moldings are one of the essential part, mostly used to decoration in traditional buildings, because of their wide surfaces. Moorish molding, the artist's goal in this style to cover all surfaces and to get rid of empty space completely, for that they used more than one way to get that. They had started the transition from small to large, till the whole facade be to decorated. That was the reason that the molding in some places disappear, their place was taken by decorations at the surface. It showed that geography, geology, climate, policy, history had the same effect but the religion thought had the majority effect on it. On the other hand, Greek molding was introduced in order to produce refined effects of light and shadow on the surrounding with motives, patterns, etc. The artists in this style were known for portraying according to religious beliefs mostly. The geography and geology were effective on decorations, because they reflected from nature either individually or collectively. The antimony flower, acanthus leaf, organisms and animals played an active role in the decoration field. Where the wood was introduced, it was well spaced and occupied the entire depth of the molding. Greek moldings were always conical sections. But every effort was made for the detailed presentation; the Greeks used trapezoidal brackets only on the side of the entrances, as in Erechtheum. The political factor was not nearly, because the Greek people were known for democracy mostly. As for the historical factor, the effect was evident as previous civilizations influenced on the molding decoration (Table 1).

Table 1. Comparison of Moldings

\begin{tabular}{|l|l|l|}
\hline \multicolumn{2}{|c|}{ Moorish } & \multicolumn{2}{|c|}{ Greek } \\
\hline
\end{tabular}


Architectural elements had been used together with decoration in history. Moorish made to stylized decoration having inscriptions, plant motives, geometric patterns on the surfaces of architectural elements. These engineering formations are mimic in Islamic art, apart from the diagnosis of forbidden life and statues in religious thought. In this case, it can be briefly said that climate and religion were the most important factors in these architectural elements. The other four factors had nearly the same effect on it. On the other part, Antique Greek decoration on the architectural element, had too much influence from the religion and history factor, while the Greek embellishments and units derived from other civilizations (Egyptian and Assyrian civilization) some motives such as balsam, palms, papyrus, antimony and some types of winged animals. The other factors had nearly effect on this type (Table 2).

Table 2. Comparison of Architectural Elements.

\begin{tabular}{|c|c|}
\hline Moorish & Greek \\
\hline 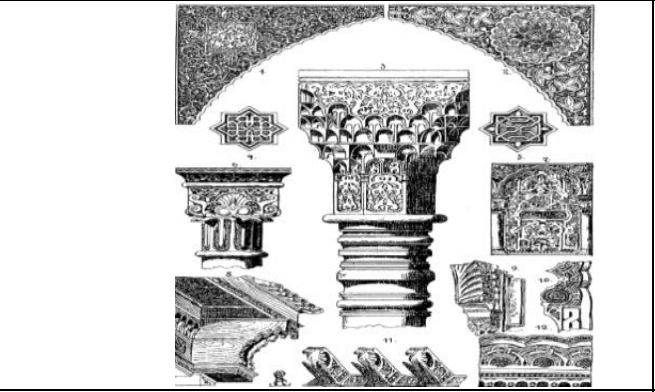 & sisis \\
\hline $\begin{array}{l}\text { Ornament from the Caliphate in Granada (Speltr, } A . \text {., } \\
\text { 1959). }\end{array}$ & $\begin{array}{l}\text { Various Ornament from Greek (Speltr, } A . \text {, } \\
\text { 1959). }\end{array}$ \\
\hline
\end{tabular}

The column is not only an important structural element but also decorative in historical buildings. The capitals were particularly decorated and also the column of the Moorish was commonly decorated completely. It was affected by nature and the local material. Also, both climate and religion factors had the same effect on the decoration of capital and shaft of the column, while the policy and history were didn't directly on it. The column, itself was far from greatness, and it is coming accurate and graceful, the crowns were decorated with harmony. Moorish artists relied on escape from the void, so they built the interior walls - often entirely - with decorations neatly distributed from the bottom to the top. The Greek column, like Moorish one, influenced by nature and their regional material "white marble", though the history effect on this type of a column of the early civilizations. Also, it can be said that religion and policy did not affect too much on the artist of this style like Moorish. As seen at the picture of the Ionic column, it has four volutes on capital, shaft with 24 contiguous longitudinal flutes. Above it is a square with the thresholds and above the cornices, the cornice, and above the Fenton facade (Table 3). 
Table 3. Comparison of Columns

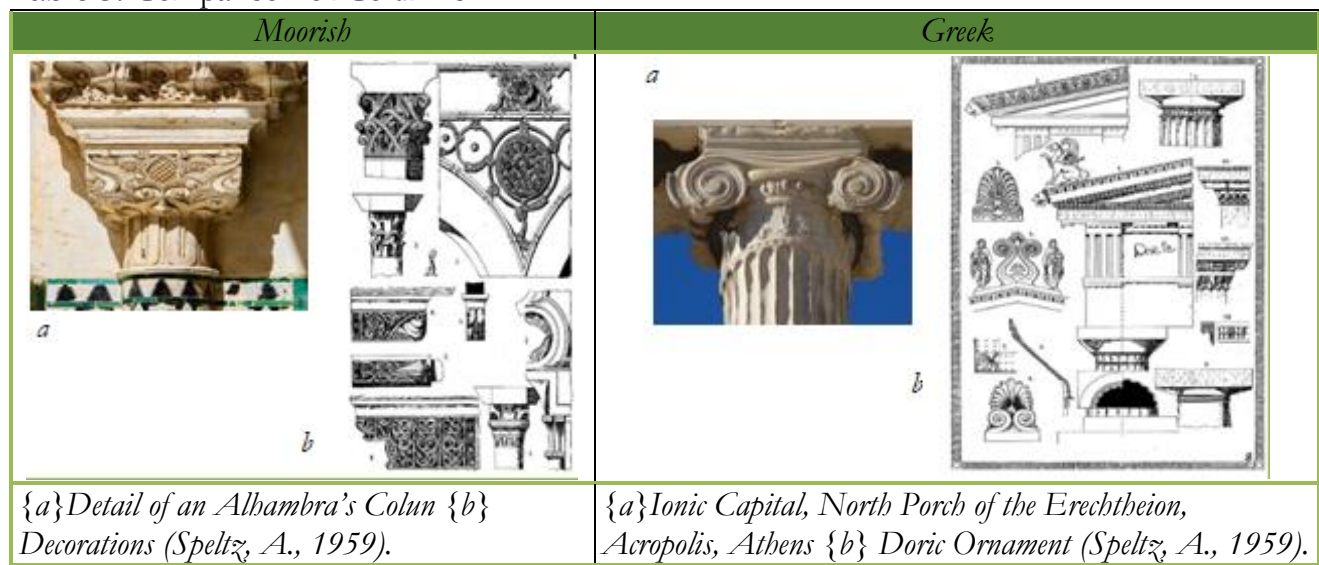

The tessellation is a decorative element that formed the repetition of geometric patterns commonly. In the Moorish art, they were interested in the geography, so they innovated natural existence distance from representation and perception in two dimensions. Therefore, the shapes are either geometrical or floral. They used the religious principles on it. The other four factors had nearly an effect on tessellation decoration of Moorish Art. Greek art also used abstraction and geometry with the use of images of gods or animals in accordance with their religious beliefs. The Greeks also used tiles and rocks in different colors to create a mosaic floor. It is said that one of the great expenses, land mosaics were used only by wealthy Greeks. While both religion and policy didn't have too much effect on Tessellation decoration.

Table 4: Comparison of Tessellation

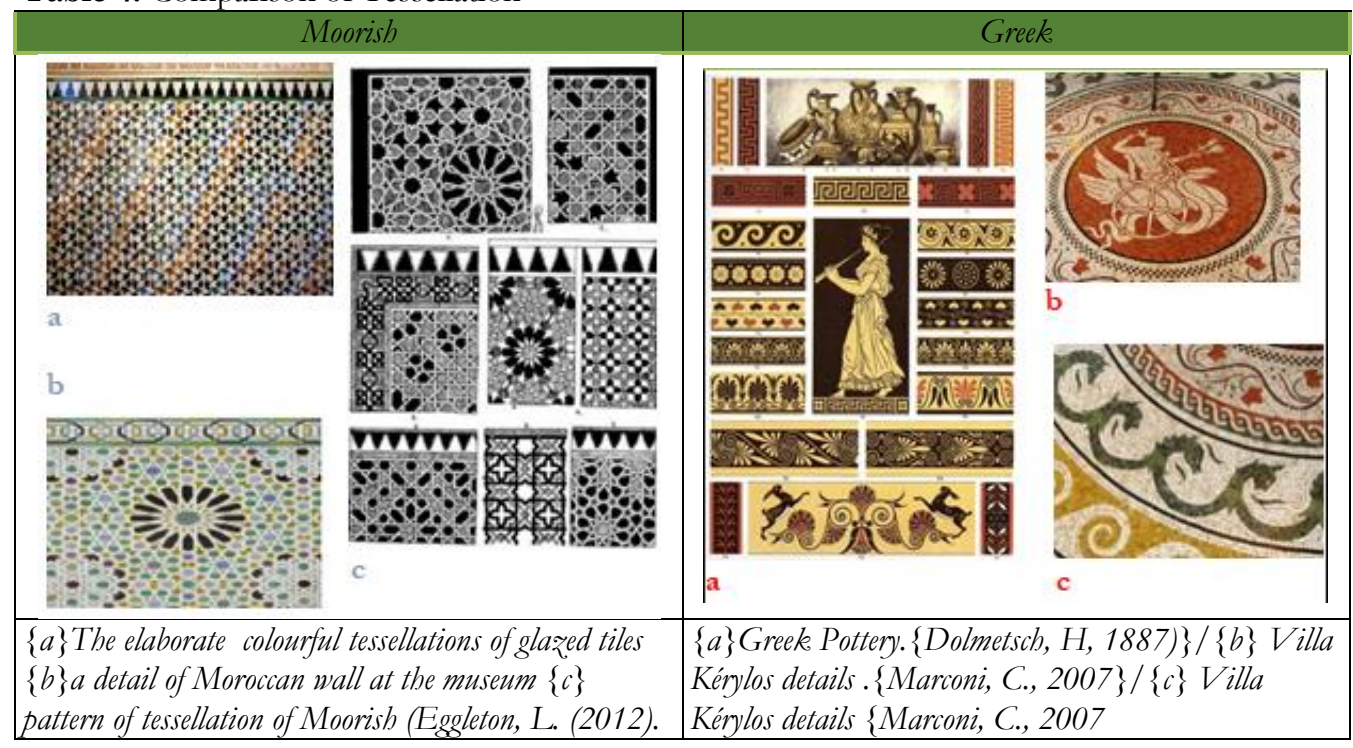


The courtyard is frequently a major part of a building despite being not a closed space, so it supplies people with many things they need. These spaces also were mostly decorated in history. An interior view of Moorish courtyard can briefly have determined the elegantly and busy, but also simple in furniture of decoration. Ceramic tiles are often used for flooring and give great appeal in hot weather. Stacked flooring is an ideal base. Mirrors enhance the interior reflecting light and decorating the walls. The effects of other factors, Religion, Policy, and History, nearly not appear directly. As for Antique Greek on the decoration to the effects of all factors in some way except the historical one. It is not too much. The Greek courtyard is usually simple, elegant and practical, having natural colors, lack of bright ones, and minimal gilding. Furniture of it is simple shape. The furniture made of natural wood and handmade upholstery of leather, the vertical orientation of all interior parts. It is characterized by high ceilings and plastered columns. The elements of decoration are vases, amphora, figures, sculptures. The Greek courtyard was white marble mostly. While Climatic was excessively hot. This gave rise to a tendency toward the small window and door openings with a courtyard for shading and spending time (Table 5).

Table 5: Comparison of Courtyard

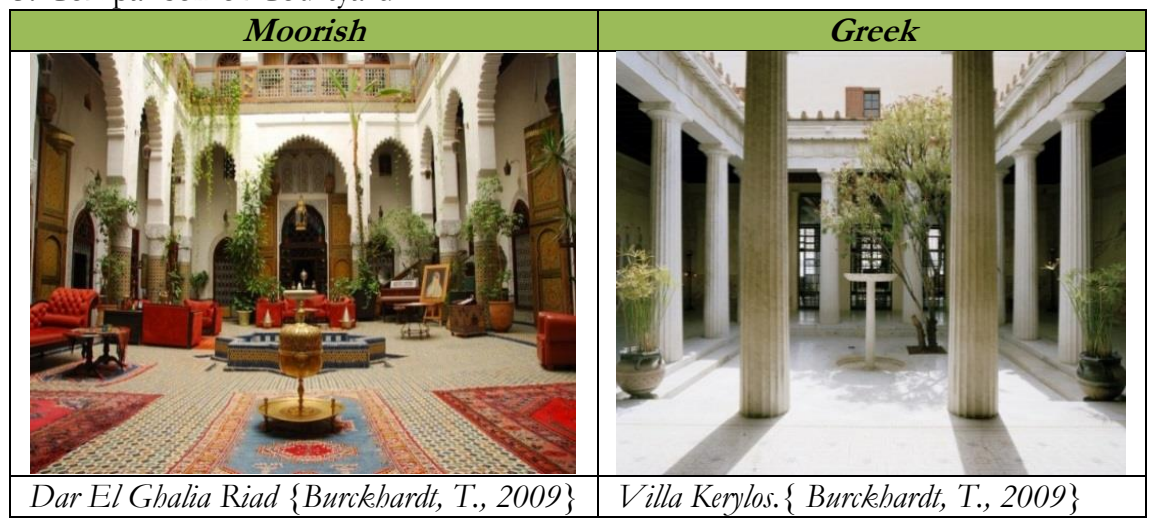

\section{Result}

Within research methodology, in order to achieve results, the Moorish and Greek decorations were compared comprehensively. Influences of factors (geography, geology, climate, religion, policy, history) that forming decoration of styles, were categorized in three rates (too much, nearly, not nearly) to determine their level on general ornaments and details of each style (moldings, architectural elements, column, tessellation, courtyard). According to this evaluation, the result illustrated to strongly how the influences being similar or different on them (Table 6).

From this data, it is clear that a majority of factors have similarities. In addition, there are little differences. Molding comparison indicated that Moorish decoration was nearly affected by geography, geology, climate, policy, history without religion. It has too much effect on the molding. Different from Moorish, architectural moldings of Greeks acquired a shape because of the effects of geology, climate, history too much. As for 
geography, policy, and religion were nearly. This showed that moldings of two styles have effects by geography and policy similarly.

Secondly, on architectural elements of Moorish, the decoration is formed by effects of geography, geology, policy, history nearly; climate and religion too much. On the other hand, Greeks decoration on them have effects of geography and policy not nearly; geology and history congruent to Moorish nearly; climate and religion too much. Thus, it can be said that the effects of geography, religion, and history are the same on the architectural elements of both styles.

The decorations on Moorish columns have effects of geography and geology too much; of climate and religion nearly; and of policy and history not nearly. The situation for Greek ones is not so different. Like Moorish, geography affected to decoration too much; geology, climate, and history nearly; policy not nearly. That is to say to indicate that both styles have effects of geography, climate, and policy at the same level.

On the decoration of the fourth part "tessellation" in illustrated table 6, there aren't any similar effects of factors. Nevertheless, the differences between them are not so excessively such as geography effects of Moorish too much, nearly in Greeks; geology nearly in Moorish, too much in Greeks; climate nearly in Moorish, nearly in Greeks; religion in Moorish too much, nearly in Greeks; policy nearly in Moorish, not nearly in Greeks; history nearly in Moorish, too much in Greeks.

The decorations of courtyards of each style have many similar effects; climate too much; religion and policy not nearly on them. But also they have different effects such as geography and geology nearly in Moorish, too much in Greeks; history not nearly in Moorish, nearly in Greeks.

Lastly, the average rates of effects on general decoration of each style were calculated. Thus it could be answered that many factors have the same effects on them. Geography, climate, history factors are the same; geology, religion, policy being different, but not distinctively.

In the comparison parts of research methodology, it was determined that the Moorish was influenced by nature, found richly in the capital of the column, the column shaft itself where the capital, column capital, Molding too. cannot separate each part because of a strong correlation by decorations, it falls under the religious philosophy they have since each the part is linked to the part and the idea of infinity so It is difficult to determine the beginning and the end in the decorative there are not pictures of any creature This is due to the religious philosophy too, while culture understanding decorative as intrinsic to a surface or object. see clearly the influence of Arabic calligraphy and there is decoration because of the geographical location, not forgetting vari-colored without any distortion of the visual. This is what distinguished the Moroccan style from its peers. 
Table 6: Comparison Result

\begin{tabular}{|c|c|c|c|c|c|c|c|c|c|c|c|c|c|}
\hline & \multirow{3}{*}{ 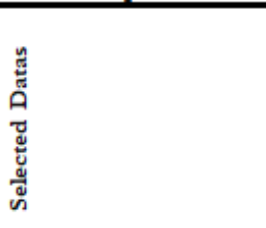 } & \multicolumn{6}{|c|}{ Moorish Decoration } & \multicolumn{6}{|c|}{ Greek Decoration } \\
\hline & & \multicolumn{6}{|c|}{ factors influence } & \multicolumn{6}{|c|}{ factors influence } \\
\hline & & 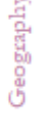 & $\begin{array}{l}50 \\
0 \\
0 \\
0 \\
0\end{array}$ & 苞 & 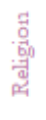 & $\begin{array}{l}5 \\
0 \\
0 \\
0\end{array}$ & 总 & 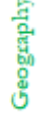 & $\begin{array}{l}b 0 \\
0 \\
0 \\
0 \\
0\end{array}$ & 苂 & 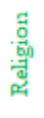 & 整 & ty \\
\hline 1 & Moldings & 2 & 2 & 2 & 1 & 2 & 2 & 2 & 1 & 1 & 2 & 2 & 1 \\
\hline 2 & Architectumal Elements & 2 & 2 & 1 & 1 & 2 & 2 & 3 & 2 & 2 & 1 & 3 & 2 \\
\hline 3 & Colume & 1 & 1 & 2 & 2 & 3 & 3 & 1 & 2 & 2 & 3 & 3 & 2 \\
\hline 4 & Tessellation & 1 & 2 & 3 & 1 & 2 & 2 & 2 & 1 & 2 & 2 & 3 & 1 \\
\hline 5 & Coustyard & 2 & 2 & 1 & 3 & 3 & 3 & 1 & 1 & 1 & 3 & 3 & 2 \\
\hline \multicolumn{2}{|c|}{ General Decoration } & 2 & 2 & 2 & 1 & 2 & 2 & 2 & 1 & 2 & 2 & 3 & 2 \\
\hline
\end{tabular}

\section{Conclusion}

Cultural sustainability is one of the essential concepts of sustainability. There is hereby established the cultural understanding of sustainability. The main idea of it is connected to identity, diversity, and personality. Within this content, decoration plays a significant role to understand cultural sustainability.

The objective of this paper was to determine the decorative orientations in the Mediterranean Architecture for sustainability. After Moorish and Greek decoration were examined, it was founded that there are particularly the similarities of motives inspired by nature in these cultures. It might result from having similar factors mostly. In addition, they were used in different compositions. In brief, for all similarities of motives, the expression is different. These similarities could account for cultural sustainability. The reasons for the difference in expression might have been the result of the many factors, times.

In addition, these findings provide additional information about cultural sustainability. Greek and Moorish decorations have their own identity and it is timeless though. Nevertheless, they had orientations from one to another despite their different directions, understandings, and expressions. Because Greek and Moorish decorations had effects of the six factors, for all different rates. Thus it could be answered that there were the decorative orientations in the Mediterranean architecture and its influence on sustainable development. Future research should consider the potential effects of factors more detailly to understand cultural sustainability on Medditerranean architecture widely. As the review of this paper suggests, people tend to feel familiar with places and buildings that have memories or carry symbols related to their cultures. Moreover, personalizing and capturing the environment creates links of cultural identity and familiarity with people, making it comfortable to live.

Also it determined that the details and decorations on the scale are small but they have the ability to expressing where people can associate them. Although it may seem as decoration is only for facades and façade beautification, it has other characteristics that 
you add to buildings, such as: identifying, locating, directing attention, setting and organizing, religious expression. Expressing identity is one of the ways to use style patterns and styles in architecture.

\section{References}

Abulafia, D. (2003),The Mediterranean in History, J. Paul Getty Museum.

Azad, M. M., Barua, A., \& Sultana, S. A Review Analysis of Ancient Greek Architecture.

Abel, C. (2017). Architecture and Identity: Responses to Cultural and Technological Change 3rd Edition.

Bloomer, K. (2016). [The Greeks]'called it KOSMOS, which means ornament'.

Barrucand, M. (2007). Moorish architecture in Andalusia. Taschen America Llc.

Burckhardt, T. (2009). Art of Islam: Language and meaning. World Wisdom, Inc.

Braudel, F. (1995). The Mediterranean and the Mediterranean world in the age of Philip II (Vol. 2). Univ of California Press.

Braudel, F. (1995). The Mediterranean and the Mediterranean world in the age of Philip II (Vol. 2). Univ of California Press.

Braudel, F. (2002). The Mediterranean in the ancient world. Penguin UK.

Bayard, E., (2012), ABC of Style: How to Know and Recognize Architecture and Furniture, Parkstone Press Ltd.

Cavendish, M. (2010). Ancient Greece: An Illustrated History. Marshall Cavendish.

Coulton, J. J. (1982). Ancient Greek architects at work: Problems of structure and design. Cornell University Press

Campkin, B. (2007). Ornament from grime: David Adjaye's Dirty House, the architectural 'aesthetic of recycling'and the Gritty Brits. The Journal of Architecture, 12(4), 367-392.

Dresser, C. (1986). Principles of decorative design (Vol. 1). Library of Alexandria.

Da Vignola, G. B., Leeke, J., \& Watkin, D. (2011). Canon of the five orders of architecture. Courier Corporation.

Elnokaly, A., \& Elseragy, A. (2013). Sustainable heritage development: learning from urban conservation of heritage projects in non western contexts. European Journal of Sustainable Development, 2(1), 31 54.

Fletcher, В. (1931). A history of architecture on the comparative method. Рипол Классик

Fiol, C. M. (1991). Managing culture as a competitive resource: An identity-based view of sustainable competitive advantage. Journal of management, 17(1), 191-211.

Garlan, D. (1995, February). What is style. In Proceedings of Dagshtul Workshop on Software Architecture (Vol. 100). Saarbruecken, Germany.

Grünbaum, B., Grünbaum, Z., Shephard, G.C. (1986), Symmetry In Moorish and Other Ornaments, Unifying Human Understanding, 1986, Pages 641-653, Pergamon Press.

Hegazy, S. M. (2015). Cultural Sustainability between Traditional and Contemporary Omani Residences-A Comparative Case Study. European Journal of Sustainable Development, 4(2), 185-194.

Hegazy, S. M. (2015). Cultural Sustainability between Traditional and Contemporary Omani Residences-A Comparative Case Study. European Journal of Sustainable Development, 4(2), 185-194.

Herrle, P., \& Wegerhoff, E. (Eds.). (2008). Architecture and identity (Vol. 9). LIT Verlag Münster.

Hamlin, A.D.F. (1916). A History of Ornament: Ancient and Medieval (New York:Century Company,

Jones, O. (2016). The Grammar of Ornament: A Visual Reference of Form and Colour in Architecture and the Decorative Arts-The complete and unabridged full-color edition. Princeton University Press.

Liu, Y., \& Toussaint, G. (2010). Unravelling Roman mosaic meander patterns: a simple algorithm for their generation. Journal of Mathematics and the Arts, 4(1), 1-11

Long, C. (2009). The Origins and Context of Adolf Loos's "Ornament and Crime". Journal of the Society of Architectural Historians, 68(2), 200-223.

Lomas, K. (Ed.). (2003). Greek identity in the western Mediterranean: papers in honour of Brian Shefton. Brill.

Loos, A. (1998). Ornament and crime: Selected essays. Riverside CA: Ariane Press.

Mitrache, A. (2012). Ornamental art and architectural decoration. Procedia-Social and Behavioral Sciences, 51, 567-572. 
Massey, J. (2013). Ornament and decoration. The Handbook of Interior Architecture and Design. A\&C Black.

Memmott, P., \& Keys, C. (2015). Redefining architecture to accommodate cultural difference: Designing for cultural sustainability. Architectural Science Review, 58(4), 278-289.

Memmott, P., \& Keys, C. (2015). Redefining architecture to accommodate cultural difference: Designing for cultural sustainability. Architectural Science Review, 58(4), 278-289.

Marconi, C. (2007). Temple decoration and cultural identity in the archaic Greek world: the metopes of Selinus. Cambridge University Press.

Marconi, C. (2007). Temple decoration and cultural identity in the archaic Greek world: the metopes of Selinus. Cambridge University Press.

Maalouf, A., (2002), Traditional Mediterranean Architecture, Ecole d'Avignon

Postalc1, I. E., \& Atay, G. F. (2018). Rethinking on Cultural Sustainability in Architecture: A Reading on Projects of Behruz Çinici

Robinson, H., (1949), The Influence of Geographical Factors Upon The Fine Arts, Geography, Vol. 34, No. 1 (March, 1949), pp. 18-29.

Robertson, M., \& Robertson, M. (1975). A history of Greek art.

Robinson, H. F., Comstock, R. E., \& Harvey, P. H. (1949). 2630001. Estimates of heritability and the degree of dominance in corn. Agronomy journal, 41(8), 353-359.

Roth, L.M., Understanding Architecture (Its Elements, History, and Meaning), Westview Press, 1993.

Schultz, P., \& Von den Hoff, R. (2014). Structure, Image, Ornament: Architectural Sculpture in the Greek World. Oxbow Books.

Speltz, A. (1959). The styles of ornament. Courier Corporation.

Spuybroek, L. (2010). The Matter of Ornament.

Sağlam, H. (2014). Re-thinking the Concept of "Ornament" in Architectural Design. Procedia-Social and Behavioral Sciences, 122, 126-133.

Shepley, M. M., \& Song, Y. (2014). Design research and the globalization of healthcare environments. HERD: Health Environments Research \& Design Journal, 8(1), 158-198.

Sitkin, S. B., \& Roth, N. L. (1993). Explaining the limited effectiveness of legalistic "remedies" for trust/distrust. Organization science, 4(3), 367-392.

Trilling, J., (2001). Te Language of Ornament (London: Tames \& Hudson.

Tanner, J. (2001). Nature, culture and the body in classical Greek religious art. World Archaeology, 33(2), 257-276.

Torabi, Z., \& Brahman, S. (2013). Effective factors in shaping the identity of architecture. Middle-East Journal of Scientific Research, 15(1), 106-113.

Vick, B. (2018). Migration of Moorish Design and Its Cultural Influences in Andalusia.

Van Loon, H.W., (1938), The Arts of Mankind, George G. Harrap \& Co.,UK.

Ward, J., (1897-1909 (v. 1, 1909), Decoration and ornament -- History, Architecture -- History, Decoration and ornament, London, Chapman and Hall.

Yang, F. (2018). Sustainable Development of Traditional Houseboat: Based on the Research of Primitive Architecture of Li Nationality in Hainan Province. European Journal of Sustainable Development, 7(3), 111-119.

https://en.oxforddictionaries.com/17.10.2019

http://faculty.wwu.edu/zaferan/Ithaca $\% 20$ Curriculum/architecture/Traditional $\% 20$ Mediterranean $\% 20$ Arc hitecture.pdf/10.10.2019

https://www.slideshare.net/Anupamaholla1/style-and-ornamentation-in-architecture/09.10.2019

https://en.wikipedia.org/wiki/Islam/20.10.2019 